14.8

\title{
Прижизненные неразрушающие исследования влажности растений в реальном времени с помощью миллиметровой спектроскопии
}

\author{
() М.П. Пархоменко, С.В. фон Гратовски, Д.С. Каленов, И.С. Еремин, Н.А. Федосеев, В.М. Колесникова
}

ФИРЭ им. В.А. Котельникова РАН, 141190 Фрязино, Московская обл., Россия e-mail: pamikle@yandex.ru

Поступило в Редакцию 15 января 2020 г.

В окончательной редакции 21 февраля 2020 г.

Принято к публикации 23 марта 2020 г.

Для реализации в селекции растений методом фоновых признаков, который требует отбирать растения со средней или низкой влажностью, предложена технология миллиметровой влагометрии. Эта технология, основанная на радиофизических методах, позволила провести неразрушающие прижизненные измерения в течение коротких и длинных промежутков времени, вплоть до непрерывных. Проведенные предварительные измерения влажности пера зеленого лука показали, что погрешность измерения влажности не превышает $1 \%$.

Ключевые слова: влажность, селекция растений, метод фоновых признаков, миллиметровые волны.

DOI: $10.21883 / J T F .2020 .10 .49793 .13-20$

\section{Введение}

Одна из важнейших проблем человечества - это проблема пищи. Производство продуктов питания отстает от роста населения на планете. Согласно исследованиям авторитетных международных организаций, если растениеводы Земли к 2025-му году не увеличат валовую продукцию растениеводства в два раза, то над двумя миллиардами людей из будущего населения Земли нависнет угроза голодной смерти. Один из способов решения этой проблемы - это повышение урожайности сельскохозяйственных растений путем создание новых сортов и гибридов с помощью генетико-селекционных технологий. Для резкого повышения урожайности необходимо в корне изменить традиционную селекцию растений.

В настоящее время в селекции растений отбирают самые лучшие растения по фенотипам (по внешнему виду). Этот метод визуального отбора имеет очень низкую разрешающую способность - из 5000 самых внешне мощных отобранных растений генетически „мощным“ оказывается лишь одно. Это происходит потому, что одно растение (генетически плохое) может попасть на поле в ямку с водой и азотом и дать очень хороший фенотип. Другое растение (генетически хорошее) может попасть на сухой бугорок без азота и дать очень плохой фенотип. Визуальный отбор по фенотипу отберет генетически плохое растение. Кроме фенотипического отбора наилучшие растения в настоящее время выявляются также с помощью аппаратных физических методов, например, путем измерения влажности почвы в прикорневой области растения. Но влажность почвы является для растения косвенным параметром. И вот почему. С точки зрения физики, растение, находящееся во внешней среде, подчиняется принципу Ле Шателье, согласно которому устанавливается динамическое равновесие между уровнем влажности воздуха и почвы („фактором принуждения“) и уровнем влажности материала, в данном случае растения („отклик“). Однако так как гигроскопичность растений, как правило, неизвестна, то в качестве параметра, адекватно описывающего состояние растений, относительная влажность воздуха и почвы („фактор принуждения“) выступать не может. Но в качестве одного из таких параметров может выступать „отклик“, т.е. уровень влажности самого материала, в данном случае растения.

Коллективом под руководством академика В.А. Драгавцева $[1,2]$ разработан принципиально новый метод в селекции растений - метод фоновых признаков, который позволяет оценить качество материнского растения не за 15-20 лет, а за 2-3 min. Обнаружены признаки, которые не имеют генетической изменчивости в популяции, но очень чувствительны к уровням факторов внешней среды, главным из которых является влажность листьев и других органов. Так, в засушливых условиях необходимо отбирать генотип, который способен максимально усваивать влажность из почвы и воздуха, а также выживать в этих условиях. У таких растений содержание влаги в листьях и других зеленых частях растений будет наибольшим. Этот генотип соответствует средней или низкой влажности и является самым ценным, засухоустойчивым генотипом. Именно его надо размножать и высаживать в засушливых условиях.

Возникает следущая задача: как выявлять такие растения? Эту задачу целесообразно решать путем неразрушающих in vivo измерений влажности различных частей этих растений, например, листьев, стебля и т.д. Для мониторинга в режиме реального времени наиболее перспективными являются электромагнитные методы, которые могут обеспечивать неразрушающие измерения 
влажности в течение как коротких, так и длинных промежутков времени, вплоть до непрерывных.

Для практической реализации контроля влажности растений предлагается технология, основанная на радиофизических методах - технология миллиметровой влагометрии. Эта технология в законченном варианте исполнения будет включать в себя датчик для измерения влажности и методику измерении.

Почему именно миллиметровая влагометрия? С точки зрения электродинамики все растения являются композитными водными средами с высоким содержанием воды. Вода является высокополярной жидкостью и имеет область диэлектрической релаксации в области микроволнового и нижней части миллиметрового (ММ) диапазонов длин волн (примерно 17-24 GHz в зависимости от температуры). Этим и обусловлен выбор частотного диапазона. Выделим основные положения, на которых базируется метод миллиметровой влагометрии [3]: 1) в частотном диапазоне вблизи частоты релаксации параметры электромагнитного сигнала миллиметрового диапазона имеют сильную зависимость от процентного состава воды в композитном материале; 2) дисперсия комплексной диэлектрической проницаемости для материалов со сложным составом в линейном приближении приблизительно равна аддитивной сумме дисперсий комплексных диэлектрических проницаемостей отдельных полярных компонент этой смеси; 3) чувствительность к содержанию воды и других дипольных жидкостей в тканях растений увеличивается с частотой электромагнитных волн в этом диапазоне; 4) поглощение волн MМ диапазона в воде превышает $15 \mathrm{~dB} / \mathrm{mm}$, что намного выше, чем у всех контролируемых материалов; 5) по мере уменьшения длины волны поглощение в воде увеличивается быстрее, чем поглощение в остальных материалах; 6) ММ волны практически не чувствительны к проводящим примесям в жидкостях; 7) значения диэлектрической проницаемости неполярных веществ на частотах ММ диапазона выходят на свои предельные значения, которые чаще всего являются константами, не зависящими от частоты. Все это позволяет с помощью ММ спектроскопии быстро оценивать влажность листьев и отбирать лучшие генотипы.

\section{1. Материалы и метод}

Для практической реализации заданной технологии на первом этапе необходимо определить комплексную диэлектрическую проницаемость листьев растений. Проведенный литературный анализ показал, что данной проблемой практически никто не занимался. В качестве исследуемых объектов нами были выбраны перо лука и лист пеперомии туполистной.

На рис. 1 показано поперечное сечение пера лука. Толщина стенки лука составляет примерно $0.25 \mathrm{~mm}$.

Пеперомия туполистная представляет собой трехслойную структуру: очень тонкий нижний слой, за

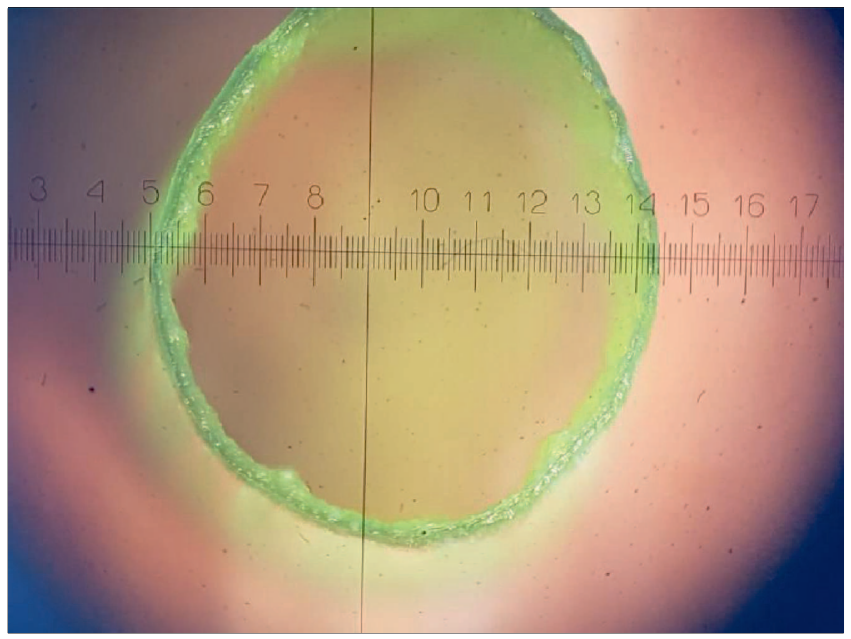

Рис. 1. Перо лука в разрезе.

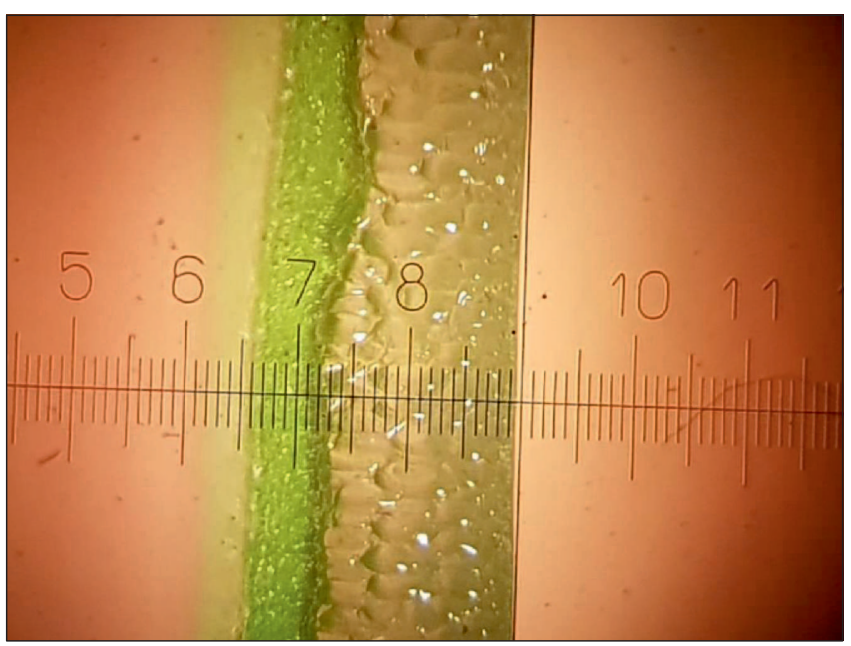

Рис. 2. Лист пеперомии туполистной в разрезе.

которым следует водянистый слой с толщиной $0.7 \mathrm{~mm}$, и затем зеленый слой кожицы с примерной толщиной $0.3 \mathrm{~mm}$ (рис. 2).

Определение влажности этих растений стандартным методом взвешивания и высушивания при температуре $105^{\circ} \mathrm{C}$ показало, что она превышает 90\%. При таком уровне влажности эти растения являются сильно отражающими объектами, поэтому для определения комплексной диэлектрической проницаемости использовался разработанный нами резонаторный метод [4]. Измерения проводились на экспериментальной установке, представленой на рис. 3. Она включает в себя панорамный измеритель Agilent, коаксиально-волноводный переход, подводящий металлический волновод и резонатор отражательного типа. Резонатор состоит из индуктивной диафрагмы, отрезка прямоугольного металлического волновода, заполненного фторопластом, и исследуемого объекта. Сильно отражающий исследуемый объ- 


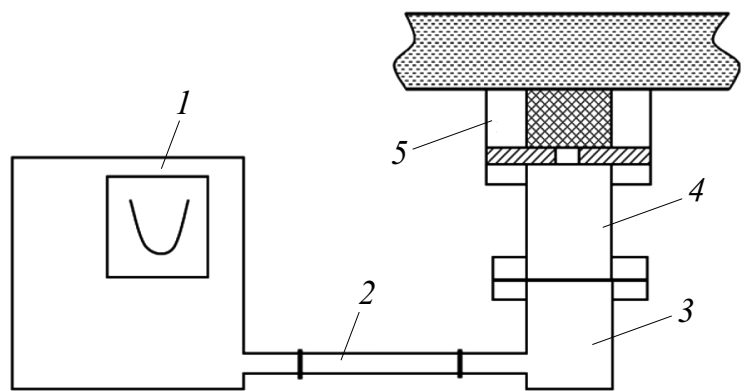

Рис. 3. Экспериментальные установки на базе панорамного измерителя Agilent: 1 - панорамный измеритель PNA-L $\mathrm{N} 5230 \mathrm{C}, 2$ - коаксиальный кабель, 3 - коаксиально-волноводный переход, 4 - подводящий прямоугольный металлический волновод, 5 - резонатор отражательного типа с исследуемым объектом.

ект выполняет роль задней стенки резонатора. В этом случае длина резонатора $l_{p}$ фактически определяется длиной прямоугольного волновода резонатора (здесь и далее индекс $p=1,2,3, \ldots$ определяет число полуволн, укладывающихся на длине резонатора). Рабочим типом волны в прямоугольном волноводе является волна $H_{10}$.

При проведении измерений сигнал от панорамного измерителя (рис. 3) через подводящий волновод поступает в резонатор, где и взаимодействует с исследуемым объектом. Отраженный от резонатора сигнал возвращается к панорамному измерителю, на экране которого отображается резонансная зависимость коэффициента отражения $R$ резонатора от частоты $f$. Панорамный измеритель позволяет посредством преобразования аналогового сигнала в цифровой сохранять в памяти прибора полученные экспериментальные резонансные зависимости, которые в дальнейшем используются для определения действительной $\varepsilon_{1}$ и мнимой $\varepsilon_{2}$ частей комплексной диэлектрической проницаемости $\varepsilon=\varepsilon_{1}-j \varepsilon_{2}$ исследуемого объекта, а также тангенса угла диэлектрических потерь $\operatorname{tg} \delta=\varepsilon_{2} / \varepsilon_{1}$.

Непосредственное определение диэлектрической проницаемости исследуемого объекта на основе экспериментальных резонансных зависимостей проводилось c помощью численного моделирования эксперимента с использованием трехмерного электродинамического программного пакета [4]. Фактически решалась обратная задача, т. е. по экспериментальным характеристикам $S$-параметров резонатора подбирались значения диэлектрической проницаемости исследуемого объекта так, что расчетные по программе $S$-параметры совпадали с экспериментальными. Эта задача решалась в несколько этапов, из которых первые два являются подготовительными. На первом этапе проводилась расчетная калибровка параметров экспериментальной установки, в ходе которой уточнялись длина резонатора, размер раскрыва $a_{1}$ индуктивной диафрагмы и ее толщина, диэлектрическая проницаемость фторопласта. Для этого для резонатора, нагруженного на дистиллированную воду при заданной температуре, снималась экспериментальная зависимость коэффициента отражения резонатора от частоты. Диэлектрические свойства дистиллированной воды в настоящее время изучены достаточно хорошо, и существует несколько расчетных методик, которые позволяют определять значения действительной $\varepsilon_{1}$ и мнимой $\varepsilon_{2}$ составляющих комплексной диэлектрической проницаемости воды в широком диапазоне частот и при разных температурах. Мы использовали методику, изложенную в работе [5], по которой и находили значения $\varepsilon_{1}$ и $\varepsilon_{2}$ воды на резонансной частоте при заданной температуре. Далее, используя эти значения $\varepsilon_{1}$ и $\varepsilon_{2}$ диэлектрической проницаемости воды, уточнялись и подбирались параметры экспериментальной установки таким образом, чтобы расчетная резонансная кривая зависимости коэффициента отражения от частоты совпадала с экспериментальной в области резонансного минимума (по резонансной частоте и глубине минимума на резонансной частоте). Второй этап включал в себя проверку расчетной калибровки установки. Для этого, используя экспериментальные резонансные кривые резонатора, нагруженного на воду при других температурах, с помощью трехмерного электродинамического программного пакета путем перебора определялись значения $\varepsilon_{1}$ и $\varepsilon_{2}$ воды при этих температурах, которые затем сравнивались с данными из [5]. Калибровка установки признавалась положительной, если расхождение подобранных значений диэлектрической проницаемости воды с данными работы [5] не превышало одного процента. Затем на откалиброванной установке для каждого исследуемого объекта, используя экспериментальные резонансные зависимости коэффициента отражения резонатора от частоты, по описанной выше методике определялись значения действительной $\varepsilon_{1}$ и мнимой $\varepsilon_{2}$ составляющих диэлектрической проницаемости этого объекта.

\section{2. Результаты}

Представим экспериментальные данные для лука. При проведении резонаторных измерений толщины одного кольца лука было недостаточно для исключения влияния интерференции, поэтому использовались три кольца. Измерения проводились в течение нескольких дней при разной влажности лука: для этого одно растение ежедневно поливалось, другое не поливалось. Результаты одного эксперимента представлены в таблице, проведем их анализ. Для лука, который не поливали: резонансная частота $30.4638 \mathrm{GHz}$; минимум коэффициента отражения на резонансной частоте равен $-24.20 \mathrm{~dB}$. Полученные путем решения обратной задачи значения диэлектрической проницаемости и тангенса угла диэлектрических потерь составили $\varepsilon_{1}=21.746 ; \operatorname{tg} \delta=1.24$. Для лука, который поливали, эти параметры составляют: резонансная частота $30.4427 \mathrm{GHz}$; минимум коэффициента отражения на резонансной частоте $-25.37 \mathrm{~dB}$. Вычис- 


\begin{tabular}{c|c|c|c|c|c}
\hline Лук & Влажность, $\%$ & $f, \mathrm{GHz}$ & $R, \mathrm{~dB}$ & $\varepsilon_{1}$ & $\operatorname{tg} \delta$ \\
\hline Не поливали & 92.9 & 30.4638 & -24.20 & 21.746 & 1.24 \\
Поливали & 94.4 & 30.4427 & -25.37 & 21.16 & 1.34
\end{tabular}

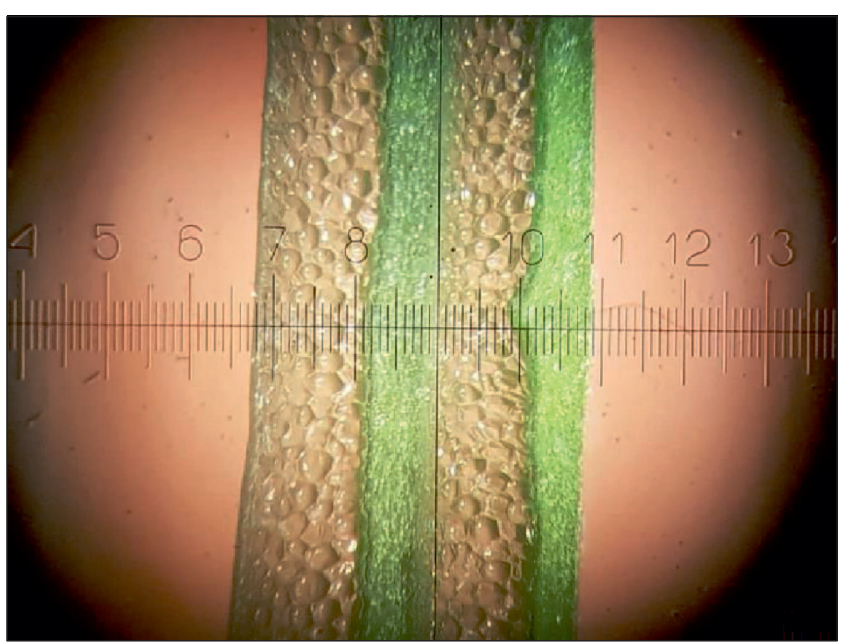

Рис. 4. Многослойная структура пеперомии туполистной. Склеены два листа.

ленные значения диэлектрических параметров равняются: $\varepsilon_{1}=21.16 ; \operatorname{tg} \delta=1.34$, т. е. потери в этом случае возросли. Большему значению тангенса угла диэлектрических потерь соответствует и большая влажность. Это подтверждается экспериментально. Определенная в этом случае стандартным методом взвешивания и высушивания влажность для лука, который не поливали, составила 92.9\%. Для лука, который поливали, она равнялась 94.4\%. Сравнивая значения влажности с полученными значениями коэффициента отражения резонатора в минимуме резонансной кривой для резонатора, который работал в режиме „недосвязи“, наблюдаем полное электродинамическое соответствие, т.е. большему значению влажности соответствует меньшее значение коэффициента отражения. Таким образом, используя калибровочную зависимость между влажностью и минимумом коэффициента отражения резонатора, мы можем предложенным методом определять влажность лука. Проведенный анализ показал, что погрешность определения влажности в данном методе не превышает $1 \%$.

Для пеперомии туполистной резонаторные исследования не обнаруживают однозначной зависимости между влажностью листьев и минимумом коэффициента отражения резонатора. Это объясняется тем, что при составлении многослойной структуры она получается неоднородной, так как в промежутке между влажными составляющими листа располагается достаточно толстый слой кожицы (рис. 4).

В проведенном эксперименте использовались два листа, в которых толстый слой кожицы был удален. Ис- следовались три комбинации соединения таких листьев и наложения их на резонатор. Полученные средние значения составили для действительной части комплексной диэлектрической проницаемости $\varepsilon_{1}=22.24$; величина тангенса угла диэлектрических потерь равнялась $\operatorname{tg} \delta=1.39$. Измеренная стандартным методом влажность составила 94.2\%.

\section{Заключение}

Проведенные калибровочные эксперименты и анализ результатов измерений показали, что метод миллиметровой влагометрии позволяет проводить прижизненное неразрушающее измерение влажности растений в реальном времени. Таким образом, предлагаемый метод удовлетворяет требованиям, необходимым для быстрого и эффективного подбора растений с целью их последующего селекционного отбора. Эти исследования требуют продолжения проведения измерений на широком классе растений.

\section{Финансирование работы}

Работа выполнена за счет бюджетного финансирования в рамках государственного задания ИРЭ им. В.А. Котельникова РАН.

\section{Конфликт интересов}

Авторы заявляют, что у них нет конфликта интересов.

\section{Список литературы}

[1] Драгавцев В.А., Макарова Г.А., Кочетов А.А., Кочерина Н.В., Мирская Г.В., Синявина Н.Г. // Агрофизика. 2011. № 1. C. 14-22.

[2] Драгавцев В.А. // Эко-потенциал. 2016. № 2 (14). С. 22-27.

[3] Meriakri V.V. // Proc. of the 2000 Material Research Society Spring Meeting, Symp AA. San Francisco, USA, 2000. Paper AA2.6.

[4] Пархоменко М.П., Савельев С.В., Фон Гратовски С.В. // Радиотехника и электроника. 2017. Т. 62. № 3. С. 276-291.

[5] Meissner T., Wentz F.J. // IEEE Tr. Geosci. Remote 2004. Vol. 42. N 9. P. $1836-1849$. 